\title{
Correspondence
}

\section{One submission to all journals}

The process of submitting a manuscript has yet to catch up with the publishing revolution that is being spurred by openaccess journals, data repositories, ORCID, Publons, PubPeer, arXiv and bioRxiv. A centralized, streamlined online-submission process that serves all journals is sorely needed to circumvent this inefficient procedure.

The service offered by Peerage of Science is a step in the right direction (see go.nature. com/2pbsby2) but it is limited by its main function as a preprintreviewing facility. And although proposals to submit manuscripts in a common format are timely (see Q. Guo Nature 540, 525; 2016 and J. P. Moore Nature 542, 31;2017), different submission systems remain a bottleneck.

Authors need to re-enter details such as contact information and keywords every time they submit to a different journal. Other, spurious data may be requested that have no bearing on the review process or publication decision, perhaps because the information is useful to the journal (submission to journals such as PeerJ is notably less timeconsuming).

In the past 20 years, the United Kingdom and the United States have each developed systems that allow prospective students to apply to several universities using the same form. If universities can create and collaborate on such a system, surely academic journals can do so too.

Tim Birkhead University of Sheffield, UK.

Robert Montgomerie Queen's University, Kingston, Canada. t.r.birkhead@sheffield.ac.uk

\section{Restore earthworms to rebuild topsoil}

Charles Darwin was right to laud the earthworm. It is a natural instrument for restoring degraded soils (see J. Davies
Nature 543, 309-311; 2017). Yet several species are already on the Red List of the International Union for Conservation of Nature. In our view, the best way to save our diminishing earthworm workforce is to use routine vermicomposting of organic wastes and to manage soils in ways that respect permaculture principles and practices.

Earthworms are ecologically crucial in the creation of healthy soils. They mineralize nutrients, either directly or by stimulating microbial activity in synchrony with plant needs, thereby increasing crop yields by $25 \%$ (see J. W. van Groenigen et al. Sci. Rep. 4, 6365; 2014). And rain filtered through worm burrows gives rise to worm-worked humus that stores $40 \%$ more moisture to sustain crops through drought (see go.nature.com/2oofvfq).

Earthworms also help to remedy other global problems, such as biodiversity decline and climate change. They reduce the need for large quantities of agrochemicals and boost carbon storage in soil through ingestion of plant residues (see http://4p1000.org). The earthworm warrants more scientific attention and investment.

Robert Blakemore VermEcology, Yokohama, Japan.

Axel Hochkirch Trier University, Germany.

rob.blakemore@gmail.com

\section{Note limitations of DNA legislation}

The draft bill on forensic DNA phenotyping (FDP) in Germany should take into account the technology's scientific and operational limitations, as well as the social contingencies regarding its use (see Nature 543, 589-590; 2017).

The high probabilities for predicting visible traits and biogeographical ancestry, as emphasized in the bill and in public debate, do not take into account the prevalence of traits in the German population. Prediction probabilities for rare characteristics can drop to less than $50 \%$ when adjusted for prevalence. Yet in practice, FDP-guided investigations will focus on rare characteristics: a positive test for dark skin, a rare trait in Germany, could much more efficiently (even if wrongly) narrow down an investigation than could a positive result for the much more common trait of light skin. Minority groups could therefore become over-represented in police investigations.

Biogeographical testing is less reliable for individuals with mixed ancestry or for those from regions that are undersampled in the reference databases. The use of test results may be premised on assumed visible features (C. Phillips Forensic Sci. Int. Genet. 18, 49-65; 2015). Biogeographical ancestry, ethnicity and appearance are therefore at risk of becoming conflated in policing practice.

Germany's police, prosecutors and forensic analysts need more statistical training to assess test results properly. The use of these technologies also requires a balanced framework of governance, including judicial, ethical and regulatory oversight by independent governmental bodies (see go.nature. com/2oq090e).

Fabian Staubach Institute for Biology I, University of Freiburg, Germany.

fabian.staubach@gmail.com On behalf of 9 correspondents (see go.nature.com/2odjphz for full list).

\section{Share names for dinosaur divisions}

Matthew Baron and colleagues propose a radical revision of dinosaur relationships (Nature 543, 501-506; 2017). I suggest that borrowing from the field's rich history could help to prevent unnecessary confusion.

Historically, Saurischia is one of the two basic divisions of dinosaurs, the other being the Ornithischia (H. G. Seeley Proc. R. Soc. Lond. 43, 165-171; 1887). Saurischia comprises the mostly carnivorous Theropoda, which includes Tyrannosaurus rex (and birds as a subgroup), and the primarily herbivorous Sauropodomorpha, such as Diplodocus longus. The point of potential confusion in Baron and colleagues' proposal is that the authors retain the name Saurischia while removing the Theropoda.

A different scheme might be less confusing. For instance, Sauropodomorpha could be retained as the clade that comprises all species closer to Diplodocus than to theropod dinosaurs. In Baron and colleagues' analysis, this would differ only slightly from its use over the past several decades by including the limited group of late Triassic carnivorous Herrerasauridae.

Alternatively, the term Pachypodosauria, devised by Friedrich von Huene in 1914, could be revived. Initially used to unite larger theropods with the sauropodomorphs, the term could now be applied to a clade of dinosaurs that have four or more weight-bearing toes, as distinct from their lighter-footed ornithoscelidan sister taxon with three weight-bearing toes. Such a scheme would accommodate the two competing hypotheses: a conventional Saurischia-Ornithischia split versus the new PachypodosauriaOrnithoscelida division.

Thomas R. Holtz University of Maryland, College Park, USA. tholtz@umd.edu

\section{CONTRIBUTIONS}

Correspondence may be sent to correspondence@ nature.com after consulting the author guidelines at http://go.nature.com/ cmchno. 